\title{
Weaving the Common Threads of Simulation and Formation studies in Archaeology
}

\author{
Benjamin Davies, The University of Auckland, New Zealand
}

\begin{abstract}
Computer simulation is a tool increasingly used by archaeologists to build theories about past human activity; however, simulation has had a limited role theorising about the relationship between past behaviours and the formation of observed patterning in the material record. This paper visits the argument for using simulation as a means of addressing the gap that exists between archaeological interpretations of past behaviours and their physical residues. It is argued that simulation is used for much the same reason that archaeologists use ethnographic or experimental studies, and that computational models can help to address some of the practical limitations of these approaches to record formation. A case study from arid Australia, examining the effects of episodic surface erosion on the visibility of the record, shows how simple, generative simulations, grounded in formational logic, can be used to compare different explanatory mechanisms and suggest tests of the archaeological record itself.
\end{abstract}

Keywords: Formation, simulation, digital archaeology, Australia

\section{Introduction}

In February of the year 2000, a low pressure system moved across western New South Wales, Australia, bringing heavy rains to many parts of the region, including the Nundooka study area near Fowlers Gap Arid Zone Research Station. Archaeologists working in the area had surveyed the surface archaeology during the previous year, and returned to survey again the following winter. In their follow-up survey, they noted an abundance of vegetation that obscured many parts of the study area that were once highly visible. It was also observed that erosion in some places had winnowed away topsoils, exposing a greater abundance of smaller artefacts, while concentrated flows in other parts of the study area decreased the number of small flakes. This serendipitous co-occurrence of an archaeological survey and a large-scale fluvial event is an example of a 'natural experiment'; an opportunity to evaluate the effects of a natural process that is otherwise difficult or impossible to control (Tucker, 2009). The effects observed at Nundooka were not uniform across Fowlers Gap landscape: for example, stream action in another study area knocked out previously recorded surfaces dating back to the mid-Holocene. However, these are only two expressions of this process within a range of settings that went mostly unobserved. Additionally, the event-driven natural processes that condition the surface record in this part of the world, such as large scale flooding and aeolian sediment transport are fairly rare occurrences, and being in a position to measure their effect on the archaeological record at all is even rarer given their unpredictability. The next such opportunity may not come for another decade, after the field seasons for the project had already ceased. 
Natural experiments such as these are useful for providing primary observations and generating hypotheses in systems that are otherwise difficult to experiment with. However, relying on these to understand large-scale processes would make building and testing theories about the landscape history of place like Nundooka untenable. Archaeological theory-building depends on the association of arrangements of material objects observed in the present with processes that occurred during the past to form them. However, the sum of those formational processes cannot be observed, only the patterns they leave behind. Archaeologists cannot experiment directly with many suspected generative processes, because they occurred over long periods of time and involved subjects that are logistically or ethically impossible to constrain (e.g. humans, ecosystems, etc.). This is especially true of human behaviour considered beyond the ethnographic scale, where substantial variation might be expected to occur over both time and space.

To overcome the gap between observed patterns and suspected processes, many have emphasised the need for appropriate analogues (e.g. Dunnell, 1992; Gifford-Gonzalez, 1991; Gould, 1965; Johnson, 2010, p. 50; Murray and Walker, 1988; Wylie, 1985). However, faced with the expansive and temporally inconsistent nature of archaeological record, some difficult questions arise. Most immediately, what analogues exist for landscapes or regions, particularly analogues that are capable of being observed simultaneously? Furthermore, how does one find substitutes for the time it takes for long-term generative processes to operate? The processes that operate at these scales (social, ecological, formational, or otherwise) produce emergent residues, and as such cannot be simply reduced into their constituent parts, nor can it be assumed that they can be collapsed to a past snapshot comparable with an ethnographic scene. Even if it were the case that such a reconstruction was possible, the combinations of processes which came together to produce an observed pattern are but one outcome from a host of possible historical contingencies that different combinations of processes might produce (Gifford-Gonzalez, 1991; McGlade, 2014). Outside of case-specific statements, how would such an analogy inform on general theory? In this paper, we argue that computer simulations can provide such analogues, moreover, they are a suitable means for studying of the complex entities of interest to archaeologists. These notions have been raised before, but often not in connection with the formation of the archaeological record. By highlighting similarities between the ideas behind archaeological record formation and the use of simulation for understanding the past, we hope to present them as parts of a common framework for building archaeological theory.

\section{The Common Threads of Formation and Simulation}

Connecting present day archaeological patterning to processes operating in the past has been a clear aim of archaeological research for decades (Ascher, 1961; Bailey, 1981, 1983; Binford 1981; Gifford-Gonzalez, 1991; Schiffer 1972, 1987) and consistently features in introductory descriptions of the discipline (Scarre 2013, p. 24; Renfrew and Bahn 2012, p. 11). If archaeologists aim to explain or interpret patterning in archaeological deposits with some authority, with the parallel anthropological aim of implicating some human behaviour in that explanation, then the task of the theorising archaeologist must be to develop a strong inferential link between those patterns and suspected generating processes (Murray 1999, p. 24). To study how archaeological objects come to be in their present arrangement is to study archaeological formation. 
It is not empirically sufficient to interpret processes operating in the past solely from analysis of patterns. There are several reasons why this is the case, which tend to be subsumed under the heading of equifinality. First, patterns may not be intuitively recognisable as the outcome of a given process. Such a situation might arise because the pattern itself lacks a unique structural isomorphism (Cale et al., 1989), or the observer lacks a referent pattern for comparison. The inverse notion that the same pattern might be generated by more than one process is likewise problematic (Levin, 1992; Beven, 2002; Premo, 2010). There are numerous cases where archaeologists have developed multiple models to explain the same phenomena, but defining archaeological explanations or interpretations as equifinal is questionable because their status as such may only be fleeting. Rogers (2000) notes this in the study of faunal remains, differentiating between a mathematical definition of equifinality (sensu von Bertalanffy, 1949, p. 157) that declares generative mechanisms as equifinal only when they produce precisely the same outcome, and a more colloquial definition used by archaeologists in which outcomes are not the same, but only similar. If archaeological interpretations were truly equifinal, then there would be no hope of discerning between the proposed generating processes, nor much need to. Alternatively, if outcomes are only equifinal in the sense that it is difficult to compare generating archaeological models in terms of the available data, they might be better described as provisionally under-determined by the data at hand (Laudan and Leplin, 1991). This may be in part due to a lack of comparable data, but may also be due to a lack of appropriate mechanisms for discerning between patterns in existing data. In both of these cases, the problem of under-determination between presented alternative explanations is potentially a resolvable one.

For historical sciences, in order to associate a pattern with a presumed process acting in the past, the acceptable range of variability for outcomes of the process in question, with respect to the pattern observed in the archaeological record, must be established; in other words, its material signature. This is what Binford (1981, p. 26) refers to as 'criteria of recognition' for the operation of past processes, and speaks to 'performance' standards identified by Dunnell (1992) as fundamental for empirical studies. These cannot be observed directly, so analogous systems must be used as surrogates. This is sometimes achieved through actualistic studies under controlled conditions (e.g. Dibble and Rezek, 2009), natural experiments, or through ethnoarchaeological studies of contemporary social groups (e.g. Skibo, 2009). These kinds of observations take place in the present, so to be applied to the past the causal relationships between the analogue process and the analogue pattern must be assumed to be uniform through time and across space. In instances where such uniformitarian assumptions are warranted, archaeologists can evaluate 'how an object interacted with its environment [in the past] with exactly the same certainty as if it were moving in front of us' (Dunnell, 1992, p. 215).

It is fair to say that many simulating archaeologists employ computational models to overcome the barrier of being unable to observe or experiment with processes occurring in the past (Aldenderfer, 1991; Kohler, 2000; Premo, 2010), which is much the same reason that formation-oriented approaches make use of ethnographic analogy and experiments. Differences certainly exist between earlier formation approaches and more recent conceptualisations of archaeology as a model-based science, but many of these are arguably superficial when compared with the obvious similarities. Specifically, the language adopted by model-based archaeological studies is primarily experimental, viewing simulation 
as a 'virtual laboratory' (Kohler et al., 1996; cf. Binford, 1981, p. 29). Both simulation and formation-based approaches such as middle-range theory and behavioural archaeology have been promoted to generate a better understanding of variability in the outcomes of processes that formed the archaeological record (Aldenderfer 1991, p. 222). Premo (2007, p. 27, emphasis in original) notes this when he refers to exploratory agent-based simulation as a form of 'experimental ethnoarchaeology', and argues that:

'Exploratory agent-based models start with theory. They allow us to build a set of expectations that can then be evaluated with observed empirical data. As a result, they can facilitate tests (of our assumptions or of a particular hypothesis) that do not suffer from the same pernicious circularity that confounds studies that use the same set of archaeological data both to formulate hypotheses about archaeological formation processes and to test them.'

Ethnoarchaeological and actualistic studies have been historically limited by the inability to extend observation over large spatial and temporal scales, or to study social processes at higher orders of social organisation. Processes that generate discrete phenomena, like cut marks on bone, can be observed in experimental or field settings, and that knowledge of the causal relationship between pattern and process can be effectively leveraged via uniformitarian assumptions to interpret the signatures of some causal mechanisms to the exclusion of others. But understanding higher-order phenomena, such as why different frequencies of cut marks occur in different places, or why the relative frequencies of different kinds of cut marks changes over time, is not simply a matter of doing more bone modification experiments. The systems that generate these kinds of patterns may be composed of individual instances of bone modification, but are connected by relationships that may or may not be linear, or may be associated with elements that do not bear directly on the formation of modification signatures but influence other components of the broader archaeological pattern. The resultant phenomena exhibit emergent qualities that are not captured by a study of the proximal causal mechanics alone. On this matter, persisting in using middle-range analogues of lower-order phenomena to directly assess higher-order phenomena will inevitably result in more instances of equifinality (at least as understood archaeologically; see Gifford-Gonzelez, 1991).

This conundrum parallels the motivations that drive research in the field of complex systems. Among the main tenets of complex systems theory are the notions of self-organisation and emergence; in other words, that complex, higher-order structures that are identifiable, describable, and in many cases quantifiable entities unto themselves can emerge from simpler, lower-order interactions of individual system components (Anderson, 1972; Bak et al., 1987; Weaver, 1948, p. 539). Being properties of evolving systems, defining emergent structures necessitates the incorporation of time and space, operating at scales both synchronous with, and different from, those of their constituent parts (Levin, 1992, p. 1950; Goldstein, 1999, p. 50). These ideas correspond well with contemporary conceptualisations in archaeology of the relationships between individual agency within socio-ecological systems (McGlade, 1995; Bintliff, 2008, p. 160), facilitating the application of simulation methods in this area, but it also meshes ideas associated with archaeological formation that view the record as being perpetually in a state of becoming (e.g. Ascher, 1961; Schiffer, 1976; Binford, 1981; Bailey, 1983; Lucas, 2008; see also Pred, 1984). 
There have been numerous applications of simulation in archaeological research, with the number increasing in recent years. The lion's share of these studies emphasise sociocultural evolution and human-environment interactions, with model outcomes that often reflect changes in the social entities or environments being modelled. On the other hand, few studies presented to date are focused on processes that directly influence the archaeological record. Costopoulos (2010, p. 24) argues that while they might trade in social or ecological theories, generalised archaeological simulations should be capable of including elements that bear directly on material residues. This may be true, but based on the record of published studies (see Lake, 2014, for example), this connection is not usually emphasised, and it has been argued that the promise of simulation to address questions about complex systems in the past has not translated easily to inferences regarding the formation of patterning in the material record on which archaeological inferences are made (Barton, 2014, p. 310).

Archaeological simulation is not unique in its limited engagement with formation processes. While the actual feelings of archaeologists are difficult to gauge, there is a sense that while formation is generally recognised as an essential component for making archaeological inferences, it is not given as much attention as other areas of archaeological interpretation. This sentiment is encapsulated in an informal exchange between Michael Shanks and Michael Schiffer (Rathje et al., 2013, p. 35). Schiffer, when asked why formation studies had not been more enthusiastically embraced by archaeologists, responded:

\begin{abstract}
'Although I really don't know, I can furnish one facile answer. Archaeologists do get it, but they recognize that taking into account formation processes complicates the research process, burdening us with labor- and thought- intensive activities. Many archaeologists are willing to take shortcuts because accolades flow swiftly and surely to those who craft fascinating and far-reaching inferences consistent with the latest theoretical fashions - regardless of how firmly they have been grounded in archaeological principles and archaeological evidence.'
\end{abstract}

This notion, that researchers will choose more-interesting-but-empirically-shaky research over less-interesting-but-empirically-sound research, could be read simply as cynicism, although it has been suggested that similar types of decisions in other disciplines are endemic to the contemporary academic research climate (e.g. Nosek et al., 2012). It also echoes an earlier dilemma discussed in Wylie's (1985) treatment on the use of analogy in archaeology, in which the search for meaningful interpretations is contrasted with the more menial task of accounting for physical arrangements of artefacts. According to this characterisation of the dilemma, formation studies in isolation represent an intellectually sterile form of 'artifact physics' to be contrasted with a more fulfilling interpretive archaeology which is ultimately more speculative (DeBoer and Lathrap, 1979, p. 103). Rather than operating as a common interpretive framework for the study of the archaeological record, the study of formation is instead viewed a spoiler, highlighting the same disconnect between the informational content of archaeological deposits and the interpretations derived therefrom (Shott, 1998, p. 321; McGuire, 1995, p. 174; Wood and Johnson, 1978, p. 369). 
In sum, simulation and formation-based approaches share common philosophical strains and goals, in particular their use of analogical reasoning, and an interest in explanation of emergent phenomena through the interaction of individual system components. However, simulation and formation concepts are rarely used in tandem, despite simulation's ability to extend explanatory models beyond a local, ethnographic scale. The following case study demonstrates one way that simulation can be effectively used to help understand the processes that form patterns in the archaeological record, and how the knowledge gained from simulating formation processes can help to differentiate between different formational mechanisms and, ultimately, interpretations of past human activity.

\section{Simulating Formation of Surface Archaeological Deposits: an Australian Case Study}

The case study comes from the arid region of western New South Wales, Australia, which has been occupied by humans for more than 50 thousand years. The land is predominantly low $(<250 \mathrm{~m}$ elevation) and flat, with most surface undulations surrounding creek catchments and ephemeral lakes in the form of low hills and dunes. The Darling River is the primary drainage for the region, which experiences extreme fluctuations in flow rate, and dry and ephemeral lakes are common features in the river's past and present overflow areas. A long-term history of erosion has exposed extensive areas of subsurface sediments and concentrations of artefacts, presenting a surface record that is highly visible and notoriously difficult to interpret (Pardoe, 2003).

Among the objects commonly found in the region are heat-retainer hearths (Figure 1), which are manifest as concentrations of fire-altered stone. Ethnographically, heat-retainer hearths were constructed by digging a shallow pit and lining it with stones. A fire was built on the stones, and then food was placed on the stones and covered with hot ashes for cooking. As sediments surrounding a hearth erode away, hearths appear as dense piles or caps of fired rock that eventually disintegrate as the baked earth holding them together is winnowed away. Sometimes, these caps protect charcoal which can be used to provide a radiometric date (Fanning et al., 2009).

Radiocarbon data obtained from the Rutherfords Creek study area, about 30 kilometres east of the town of White Cliffs, shows increasing frequency of these features through time. Similar patterns in large radiocarbon databases around Australia have been identified, stoking longstanding debates over the population history of the continent and the presence or absence of a definable period of socioeconomic 'intensification' during the late Holocene (Smith and Ross, 2008; Williams, 2013). Alternatively, this pattern has been suggested to instead be the result of time-dependent decay on the archaeological record (Holdaway et al., 2008). In addition to this trend, hearths appear to be clustered in time, interspersed with gaps where hearths are less frequent. These gaps have been shown to broadly correspond with palaeoenvironmental proxies for aridity, and have been explained as temporary periods of abandonment (Holdaway et al., 2010) or changes in ranging behaviour (Smith, 2013). Most of the disagreement is over whether the increasing frequency of dates is due to population growth or loss of preservation.

Outlining assumptions that should accompany the use of summed radiocarbon data as a proxy for human population history, Contreras and Meadows (2014, p. 606, emphasis in 
original) argue that researchers must be able to demonstrate that the link between production, preservation, and analysis of datable organic material and population in that case is sound'. Whether or not a link between these three aspects of demographic reconstruction from summed radiocarbon data has been made, and made soundly, for surface deposits western New South Wales is debatable. For instance, while the use of data transformations to account for differential preservation in these surface deposits has been advocated in some instances (e.g. Smith, 2013), taphonomic corrections assume a decay relationship between time and age that does not incorporate the specific effects of formational processes on the condition of deposits at the time of recording (see Williams, 2012 , p. 585). If this is the case, then it is necessary to understand how formation processes affect not only the preservation of these deposits through time, but also their visibility in the present, if radiometric dates obtained from surface deposits in western New South Wales are to be used in reconstructing population histories.

These two properties, preservation and visibility, are in large part controlled by the sedimentary history of the deposit, as the local rate of sedimentation determines whether a deposit is buried or exposed, and whether it is subject to surface geomorphic processes or not (Waters and Kuehn, 1996; Ward and Larcombe, 2003). Differences in the relative frequencies of erosion and deposition of sediment over time and space are likely to produce different patterning within the chronological distribution of discoverable features in surface deposits (to say nothing of subsurface features). Fanning and colleagues (2007; sensu Renwick, 1992) propose a model of 'episodic non-equilibrium' to describe the processes forming the surface archaeological record in western New South Wales, in which largescale, intermittent geomorphic events relocate sediments within low relief creek valleys, with the effect of either masking or exposing archaeological materials lying on the surface. Since shallow slopes prevent overland flow from reaching velocities capable of moving larger objects (>20 mm) (Fanning and Holdaway, 2001), the result is a set of lagged artefact deposits seated on top of 'a mosaic of differently aged surfaces many of which lie adjacent to one another' (Fanning et al., 2007).

A simulation was produced to explore the effects of episodic erosion and deposition on the distribution of ages in visible surface hearths (Davies et al., 2016). In the simulation (Figure 2), agents move randomly from point to point within a gridded space, constructing hearths at a constant rate per annual time step. If nothing else were to happen, the record would show no change through time. Hearths contain a carbon age which records the date the hearth formed in years before present. Grid cells also contain a set of sedimentary layers, each of these also containing an age, with new hearths being constructed on the surface. At a given interval (10,50,100, or 200 years), an event will occur with one of two outcomes; erosion or deposition. If erosion occurs, the youngest layer of sediment is removed, and any hearths situated on that surface lose their charcoal and become inaccessible for radiocarbon dating, while surfaces underneath become visible. If deposition occurs, a layer of sediment is added to the cell, and any hearths visible on the surface become hidden and thus undetectable in a surface survey. At the end of each simulation run, a sample of the hearths sitting on the surface is taken and compared to the chronology reconstructed from them. The simulation takes place between 2000 BP and present; the period of interest for the patterns discussed above. An Overview, Design Elements, and Details document describing the simulation in more detail is available as an appendix. 
An initial test (Figure 3, black envelopes) showed that records produced by the simulation demonstrated common features under either highly depositional or highly erosional features, as both would have the effect of obscuring the majority of older dates, leaving the surface consisting of mainly younger dates. Also, as the duration between sedimentary episodes increased, obvious gaps appeared in the simulated chronometric sequences. This was the result of the obscuring processes operating over the entire landscape; if this were modulated and a percentage of surfaces remained stable through the sedimentary events, the gaps would disappear. Gaps in this model occur because events either bury hearths or wash away their charcoal; this is a very different mechanism from the more behavioural explanation of human absences. This allows a theoretical statement to be made with respect to the simulation and the real world: if the real world operates in a way analogous to that in the simulation, then we would expect that a proxy not similarly effected by erosion would demonstrate a more continuous record if human absences were not taking place.

This theoretical statement was assessed using a second proxy: optically-stimulated luminesce (OSL) dates from hearth stones. The stones, which are heavier than charcoal, are not affected by surface erosion in the same way, remaining mostly in place during low intensity sheetwash erosion (Fanning and Holdaway, 2001). In the simulation, this was accomplished by separately sampling hearths that are visible and contain charcoal (radiocarbon) and those that are merely visible (OSL). The results of this exercise show that the model produces the expected differences between the proxies (Figure 3, grey envelopes). This provides a means of evaluating whether gaps were the product of erosion or human absences, as human absences would be expected to produce gaps in both proxies.

To assess these findings, a set of 106 hearths from Rutherfords Creek were sampled and OSL recordings were obtained (Rhodes et al., 2010). Of those, 103 returned values within the last 2000 years. When compared to the radiocarbon data (Figure 4, black), the curve of the OSL data (Figure 4, grey) is somewhat shallower, but more striking is that periods of time that exhibit substantial gaps or clusters in the radiocarbon data are for the most part absent from the OSL chronology. For example, the clustered period between 367 and 422 $\mathrm{BP}$, containing 25 radiocarbon dates, contains only four dates in the OSL record. If fluctuations in the frequency of radiocarbon dates were due to human population dynamics, then we would expect them to occur in the population of archaeological features, rather than their components. Instead, the reverse appears to be the case here, which is more in keeping with the mechanics of the simulation.

\section{Discussion}

The results of the simulation used above show how a sedimentary system, operating under varying parameterisations of an episodic disequilibrium model (Fanning et al., 2007), might affect the archaeological signal of a uniform model of human activity. Sequential sedimentation and/or erosion events over time can transform a steady chronological signal into a record that is biased toward the present and containing episodic gaps. While this is partly an outcome of decay by post-depositional processes operating on deposits over time, the combined effects of differential visibility and preservation has the capacity to produce patterning qualitatively similar to those used to argue for population dynamics in Australian prehistory. 
There are three areas that we believe enabled the simulation described above to work effectively as an analogue for the past. The first is simplicity of the underlying model. Bevan (2015, p. 1478) noted recently that the complexity of the past is not itself justification for complicated analyses, urging for that '[s]implicity of approach remains a great virtue'. This echoes calls by Premo (2010) for more low-level theory building by way of simple, exploratory models in which the outcomes are well understood with respect to the mechanisms that produced them. The Australian case study uses a model with very simple mechanisms that captured the core logic of geomorphic processes thought to be operating in these creek beds, permitting the assessment of the mechanisms under a range of parameter configurations. This facilitated theoretical statements to be made about the causal relationships between observable sets of activities (i.e. hearth building and sediment movement) and observed arrangements of objects within the simulation (i.e. datable hearths on the surface).

The second is that the patterns of interest within the simulation are produced generatively. This use of the term generative derives from the concept of 'generative social science'; a paradigm founded on the notion that, by virtue of the specifications of micro-scale behaviours being known ahead of time, showing a simulation to be capable of generating macro-scale patterning by way of those specifications is sufficient to explain the patterning; put otherwise, 'if you didn't grow it, you didn't show it' (Epstein, 2006). The larger-scale patterning in the case study used here emerges from sets of micro-scale rules (i.e. individual agents build hearths at a given rate, individual grid cells erode or aggrade probabilistically at given intervals). Lake (2015, p. 25), examining the epistemological status of agent-based simulation in archaeology, argues that models should 'be generative with respect to the problem at hand'. This means rather than try to grow all components of a society within a single model, the simulator should be judicious in their selection of what to represent within the model and how to represent it. Rather than try to rebuild late Holocene society in arid Australia, the study here focused on how particular patterns might emerge from an abstracted set of formational processes. This goal is aided by keeping models simple and limiting initial assumptions to as few possible.

The third is that the model is grounded in formational logic. By generating patterning similar to that encountered in the archaeological record, the theoretical statements made based on model mechanics and model outcomes can be applied to the archaeological record in the same analogical way that an ethnoarchaeological or experimental model would. This is not the same as saying that the record is necessarily like that in the simulation, but only that if it were, then findings from the model would be expected to hold true. The theoretical statements generated from the simulation provided a vehicle for asking new questions about the record were it like that in the simulation, suggesting tests of the archaeological record itself that helped to compare interpretations.

This is not to say that simulations used to understand the past must always be grounded in specific depositional outcomes as a rule. Insisting on this would only narrow the usage of simulation in archaeology and ignore important lessons from the discipline's history. Theorybuilding at all levels of abstraction, and the empirical assessment of those theories in terms of their capacity to generate observed patterns in material residues, can benefit from the use of computer simulation. Instead, this is meant as a call to broaden the application of 
simulation to make more inquiries at the level from which archaeological inferences are drawn: the formation of the deposit. Not all theorising in archaeology should be formational, but no archaeological theory can be successfully applied to the past absent a theory of formation for it stand on.

Ultimately, theory-building at any level is born from the ability to think critically about the way the world works. Recent technological changes have ensured that data is being collected at much higher rates than ever before, often faster than we can carefully store or document it (Bevan, 2015). However, with increasing accessibility of faster computers, free and welldocumented software, and programming skills, simulations can be used less as an end unto themselves and more as 'tools to think with'. By keeping models simple, aiming to produce patterning generatively, and connecting theoretical statements to processes that form archaeological patterning, these tools can aide us in using the archaeological record more effectively, and in discerning between competing hypotheses.

\section{References}

Aldenderfer, M. (1991) 'The analytical engine: computer simulation and archaeological research', Archaeological Method and Theory, 3, pp. 195-247. Available at: http://www.jstor.org/stable/20170216 (Accessed: 15 September 2013).

Anderson, P.W. (1972) 'More is different', Science, 177 (4047), pp. 393-396. doi: $10.1126 /$ science.177.4047.393.

Ascher, R. (1961) 'Analogy in archaeological interpretation', Southwestern Journal of Anthropology, 17 (4), pp. 317-325. Available at: http://www.jstor.org/stable/3628943 (Accessed: 19 November 2015).

Bailey, G.N. (1981) 'Concepts of resource exploitation: continuity and discontinuity in palaeoeconomy', World Archaeology, 13 (1, Miscellany), pp. 1-15. doi: 10.1080/00438243.1981.9979810

Bailey, G.N. (1983) 'Concepts of time in Quaternary prehistory', Annual Review of Anthropology, 12 (October), pp. 165-192. doi: 10.1146/annurev.an.12.100183.001121.

Bak, P., Tang, C., and Wiesenfeld, K. (1987) 'Self-organized criticality: an explanation of the 1/f noise', Physical Review Letters, 59 (4), pp. 381-384. doi: 10.1103/PhysRevLett.59.381.

Barton, C.M. (2014) 'Complexity, social complexity, and modeling', Journal of Archaeological Method and Theory, 21 (2), pp. 306-324. doi: 10.1007/s10816-013-9187-2.

Bevan, A. (2015) 'The data deluge', Antiquity, 89 (348), pp. 1473-1484. doi: 10.15184/aqy.2015.102.

Beven, K. (2002) 'Towards a coherent philosophy for modelling the environment', Proceedings: Mathematical, Physical and Engineering Sciences, 458 (2026), pp. 2465-2484. doi: 10.1098/rspa.2002.0986. Available at: http://www.jstor.org/stable/3067324 (Accessed: 8 May 2017). 
Binford, L.R. (1981) Bones: ancient men and modern myths. New York: Academic Press. Series: Studies in archaeology.

Bintliff, J. (2008) 'History and continental approaches', in Bentley, R.A., Maschner, H.D.G., and Chippindale, C. (eds.) Handbook of archaeological theories. Lanham, MD: AltaMira Press, pp. 147-164.

Cale, W.G., Henebry, G.M., and Yeakley, J.A. (1989) 'Inferring process from pattern in natural communities', BioScience, 39 (9), pp. 600-605. doi: 10.2307/1311089. Available at: http://www.jstor.org/stable/1311089 (Accessed: 7 November 2013).

Contreras, D.A., and Meadows, J. (2014) 'Summed Radiocarbon Calibrations as a Population Proxy: A Critical Evaluation Using a Realistic Simulation Approach' Journal of Archaeological Science 52 (December), pp. 591-608. doi:10.1016/j.jas.2014.05.030.

Costopoulos, A. (2010) 'For a theory of archaeological simulation', in Costopoulos, A. and Lake, M. (eds.) Simulating change. Archaeology into the twenty-first century. Salt Lake City: University of Utah Press, pp. 21-27. Series; Foundations of archaeological inquiry.

Davies, B., Holdaway, S.J., and Fanning, P.C. (2016) 'Modelling the palimpsest: an exploratory agent-based model of surface archaeological deposit formation in a fluvial arid Australian landscape' The Holocene 26 (3), pp. 450-63. doi:10.1177/0959683615609754.

DeBoer, W.R. and Lathrap, D.W. (1979) 'Making and breaking of Shipibo-Conibo ceramics', in Kramer, C. (ed.) Ethnoarchaeology. Implications of ethnography for archaeology. New York: Columbia University Press, pp. 102-138.

Dibble, H.L. and Rezek, Z. 2009. 'Introducing a New Experimental Design for Controlled Studies of Flake Formation: Results for Exterior Platform Angle, Platform Depth, Angle of Blow, Velocity, and Force' Journal of Archaeological Science, 36 (9), pp. 1945-1954.

Dunnell, R.C. (1992) 'Archaeology and evolutionary science', in Wandsnider, L. (ed.) Quandaries and quests. Visions of archaeology's future. Carbondale: Southern Illinois University, pp. 209-224. Series; Center for Archaeological Investigations Occasional Paper 20.

Epstein, J.M. (2006) Generative social science. Studies in agent-based computational modeling. Princeton: Princeton University Press. Series: Princeton studies in complexity.

Fanning, P.C. and Holdaway, S.J. (2001) 'Stone artifact scatters in western NSW, Australia: geomorphic controls on artifact size and distribution.' Geoarchaeology, 16 (6), pp. 667-86. doi: 10.1002/gea.1015. 
Fanning, P.C., Holdaway, S.J., and Rhodes, E.J. (2007) 'A geomorphic Framework for Understanding the Surface Archaeological Record in Arid Environments.' Geodinamica Acta, 20 (4), pp. 275-86. doi:10.3166/ga.20.275-286.

Fanning, P.C., Holdaway, S.J., Rhodes, E.J., and Bryant, T.G. (2009) 'The Surface Archaeological Record in Arid Australia: Geomorphic Controls on Preservation, Exposure, and Visibility.' Geoarchaeology 24 (1), pp. 121-46. doi:10.1002/gea.20259.

Gifford-Gonzalez, D. (1991) 'Bones are not enough: analogues, knowledge, and interpretive strategies in zooarchaeology', Journal of Anthropological Archaeology, 10 (3), pp. 215-254. doi: 10.1016/0278-4165(91)90014-0.

Goldstein, J. (1999) 'Emergence as a construct: history and issues', Emergence, 1 (1), pp. 4972. doi: 10.1207/s15327000em0101_4.

Gould, S.J. (1965) 'Is uniformitarianism necessary?', American Journal of Science, 263 (3), pp. 223-228. doi: 10.2475/ajs.263.3.223.

Holdaway, S.J., Fanning, P.C., and Rhodes, E.J. (2008) 'Challenging intensification: humanenvironment interactions in the Holocene geoarchaeological record from western New South Wales, Australia' The Holocene 18 (1), pp. 403-412.

Holdaway, S.J., Fanning, P.C., Rhodes, E.J., Marx, S.K., Floyd, B. and Douglass, M.J. (2010) 'Human response to palaeoenvironmental change and the question of temporal scale' Palaeogeography, Palaeoclimatology, Palaeoecology 292 (1), pp. 192-200.

Johnson, M. (2010) Archaeological theory. An introduction. $2^{\text {nd }}$ edn. New York: WileyBlackwell.

Kohler, T.A. (2000) 'Putting social sciences together again: an introduction to the volume', in Kohler, T.A. and Gumerman, G.J. (eds) Dynamics in human and primate societies: agent based modeling of social and spatial processes. Oxford: Oxford University Press, pp. 1-18.

Kohler, T.A., Van West, C.R., Carr, E.P., and Langton, C.G. (1996) 'Agent-based modeling of prehistoric settlements in the Northern American Southwest', in Proceedings, Third International Conference/Workshop on Integrating GIS and Environmental Modeling, Santa $\mathrm{Fe}, \mathrm{NM}$, January 21-25, 1996. Santa Barbara, CA: National Center for Geographic Information and Analysis, pp. 1394-1401. Available at: http://escholarship.org/uc/item/43x094z3?query=Third\%20International\%20Conference/W orkshop\%20on\%20Integrating\%20GIS (Accessed: 20 April 2017).

Lake, M.W. (2014) 'Trends in archaeological simulation', Journal of Archaeological Method and Theory, 21 (2), pp. 258-287. doi: 10.1007/s10816-013-9188-1.

Lake, M.W. (2015) 'Explaining the past with ABM: on modelling philosophy', in Wurzer, G., Kowarik, K., and Reschreiter, H. (eds) Agent-based modeling and simulation in archaeology. New York: Springer, pp. 3-35. Series: Advances in Geographic Information Science. doi: 10.1007/978-3-319-00008-4_1. 
Laudan, L. and Leplin, J. (1991) 'Empirical equivalence and underdetermination', The Journal of Philosophy, 88 (9), pp. 449-472. doi: 10.2307/2026601.

Levin, S.A. (1992) 'The problem of pattern and scale in ecology. The Robert H. MacArthur Award Lecture', Ecology, 73 (6), pp. 1943-1967. doi: 10.2307/1941447.

Lucas, G. (2008) 'Time and the archaeological event', Cambridge Archaeological Journal, 18 (1), p. 59-65. doi: 10.1017/S095977430800005X.

McGlade, J. (1995) 'Archaeology and the ecodynamics of human-modified landscapes', Antiquity, 69 (262), pp. 113-132. doi: https://doi.org/10.1017/S0003598X00064346.

McGlade, J. (2014) 'Simulation as narrative: contingency, dialogics, and the modeling conundrum', Journal of Archaeological Method and Theory, 21 (2), pp. 288-305. doi: 10.1007/s10816-014-9201-3.

McGuire, R.H. (1995) 'Behavioral archaeology. Reflections of a prodigal son', in Skibo, J.M., Walker, W.H., and Nielsen, A.E. (eds) Expanding Archaeology. Salt Lake City: University of Utah Press, pp. 162-177. Series; Foundations of Archaeological Inquiry.

Murray, T. (1999) 'A return to the "Pompeii premise"', in Murray, T. (ed.) Time and Archaeology. London: Routledge, pp. 8-27. Series; One World Archaeology 37.

Murray, T. and Walker, M.J. (1988) 'Like WHAT? A practical question of analogical inference and archaeological meaningfulness', Journal of Anthropological Archaeology, 7 (3), pp. 248287. doi: 10.1016/0278-4165(88)90010-4.

Nosek, B.A., Spies, J.R., and Motyl, M. (2012) 'Scientific utopia: II. Restructuring incentives and practices to promote truth over publishability', Perspectives on Psychological Science, 7 (6), pp. 615-631. doi: 10.1177/1745691612459058.

Pardoe, C. (2003) 'The Menindee Lakes: a regional archaeology', Australian Archaeology, 57 (December), pp. 42-53. doi: 10.1080/03122417.2003.11681761

Pred, A. (1984) 'Place as historically contingent process: structuration and the timegeography of becoming places', Annals of the Association of American Geographers, 74 (2), pp. 279-297. doi: 10.1111/j.1467-8306.1984.tb01453.x.

Premo, L.S. (2007) 'Exploratory agent-based models: towards an experimental ethnoarchaeology', in Clark, J.T. and Hagemeister, E.M. (eds) Digital Discovery. Exploring New Frontiers in Human Heritage. CAA2006 Computer Applications and Quantitative Methods in Archaeology. Proceedings of the $34^{\text {th }}$ Conference, Fargo, United States, April 2006. Budapest: Archaeolingua, pp. 22-29 [CD-ROM].

Premo, L.S. (2010) 'Equifinality and explanation: the role of agent-based modeling in postpositivist archaeology', in Costopoulos, A. and Lake, M. (eds) Simulating change. 
Archaeology into the twenty-first century. Salt Lake City: University of Utah Press, pp. 28-37. Series; Foundations of archaeological inquiry.

Rathje, W.L., Shanks, M., and Witmore, C. (eds) (2013) Archaeology in the making. Conversations through a discipline. London: Routledge.

Rhodes, E.J., Fanning, P.C. and Holdaway, S.J. (2010) 'Developments in optically stimulated luminescence age control for geoarchaeological sediments and hearths in western New South Wales, Australia' Quaternary Geochronology 5 (1), pp. 348-52. doi:10.1016/j.quageo.2009.04.001.

Renfrew, C. and Bahn, P. (2012) Archaeology. Theories, methods, and practice. $6^{\text {th }}$ edn. London: Thames \& Hudson.

Renwick, W.H. (1992) 'Equilibrium, disequilibrium, and nonequilibrium landforms in the landscape', Geomorphology, 5 (3-5), pp. 265-276. doi: 10.1016/0169-555X(92)90008-C.

Rogers, A.R. (2000) 'On equifinality in faunal analysis', American Antiquity, 65 (4), pp. 709723. doi: $10.2307 / 2694423$.

Scarre, C. (2013) 'Introduction: the study of the human past', in Scarre, C. (ed.) The human past. World prehistory and the development of human societies. $3^{\text {rd }}$ edn. London: Thames \& Hudson, pp. 24.

Schiffer, M.B. (1972) 'Archaeological context and systemic context', American Antiquity, 37 (2), pp. 156-165. doi: 10.2307/278203.

Schiffer, M.B. (1976) Behavioral archeology. New York: Academic Press.

Schiffer, M.B. (1987) Formation processes of the archaeological record. Santa Fe: University of New Mexico.

Shott, M.J. (1998) 'Status and role of formation theory in contemporary archaeological practice', Journal of Archaeological Research, 6 (4), pp. 299-329. doi: 10.1023/A:1022876302225.

Skibo, J.M. (2009) 'Archaeological theory and snake-oil peddling. The role of ethnoarchaeology in archaeology', Ethnoarchaeology, 1 (1), pp. 27-56. doi: 10.1179/eth.2009.1.1.27.

Smith, M.A. (2013) The archaeology of Australia's deserts. Cambridge: Cambridge University Press.

Smith, M.A., and Ross, J. (2008) 'What happened at 1500-1000 cal. BP in Central Australia? Timing, impact and archaeological signatures' The Holocene 18 (3), pp. 379-88. doi:10.1177/0959683607087928. 
Tucker, G.E. (2009) 'Natural experiments in landscape evolution', Earth Surface Processes and Landforms, 34 (10), pp. 1450-1460. doi: 10.1002/esp.1833.

von Bertalanffy, L. (1949) 'Problems of organic growth', Nature, 16 (January), pp. 156-158. doi:10.1038/163156a0.

Ward, I. and Larcombe, P. (2003) 'A process-orientated approach to archaeological site formation: application to semi-arid Northern Australia', Journal of Archaeological Science, 30 (10), pp. 1223-1236. doi: 10.1016/S0305-4403(02)00253-4.

Waters, M.R. and Kuehn, D.D. (1996) 'The geoarchaeology of place: the effect of geological processes on the preservation and interpretation of the archaeological record', American Antiquity, 61 (3), pp. 483-497. doi: 10.2307/281836.

Weaver, W. (1948) 'Science and complexity', American Scientist, 36 (4), pp. 536-544. Available at: http://www.jstor.org/stable/27826254 (Accessed: 20 April 2017).

Williams, A.N. (2012) 'The use of summed radiocarbon probability distributions in archaeology: a review of methods' Journal of Archaeological Science 39, pp. 578-89. doi:10.1016/j.jas.2011.07.014

Williams, A.N. (2013) 'A new population curve for prehistoric Australia' Proceedings of the Royal Society B: Biological Sciences 280 (1761). doi:10.1098/rspb.2013.0486.

Wood, W.R. and Johnson, D.L. (1978) 'A survey of disturbance processes in archaeological site formation', Advances in Archaeological Method and Theory, 1, pp. 315-381. Available at: http://www.jstor.org.ezproxy.auckland.ac.nz/stable/20170136 (Accessed: 31 August 2015).

Wylie, A. (1985) 'The reaction against analogy', Advances in Archaeological Method and Theory, 8, pp. 63-111. Available at: http://www.jstor.org/stable/20170187 (Accessed: 14 February 2014). 
Figure 1: A collection of heat-retainer hearths on an exposed surface at Rutherfords Creek

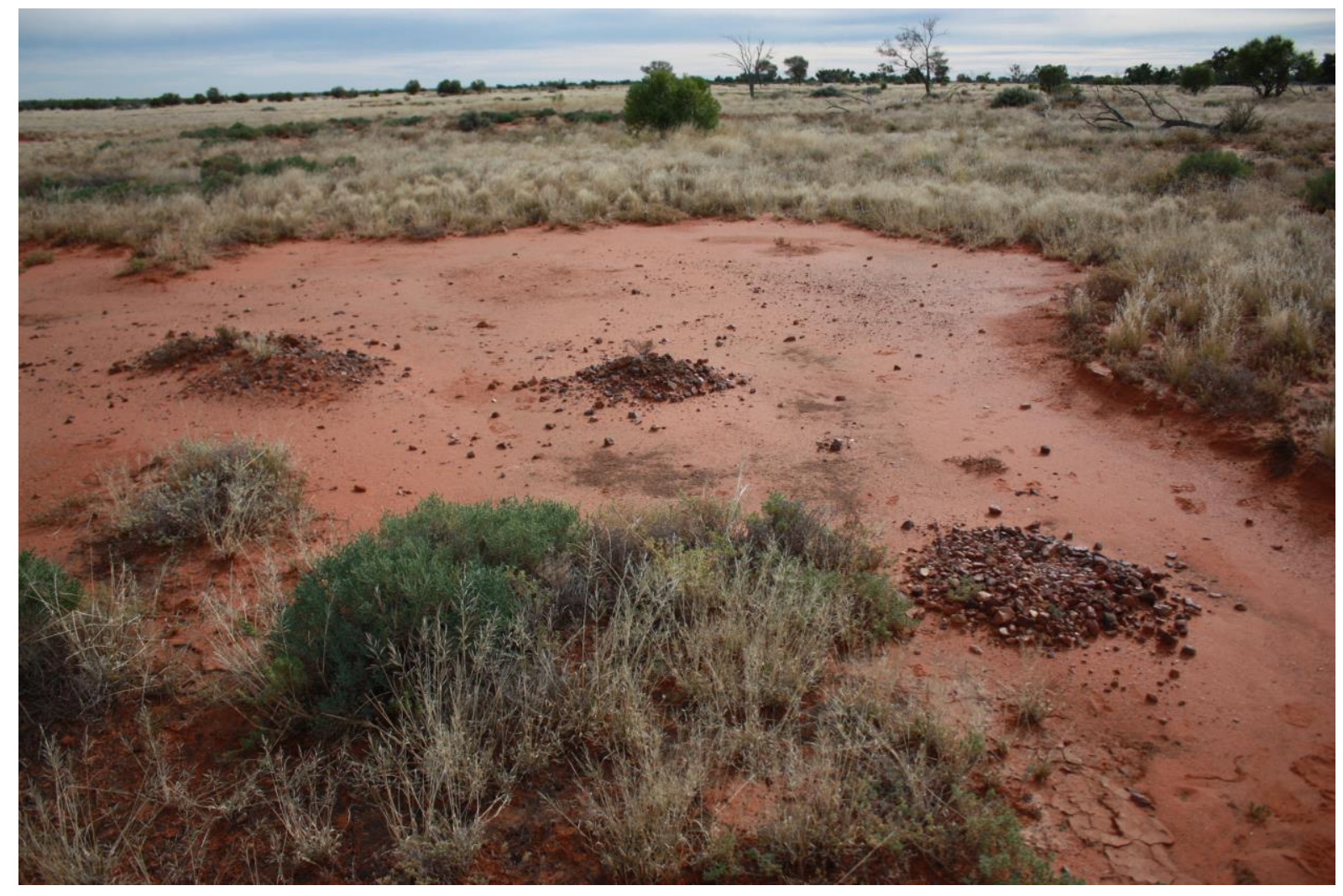


Figure 2: Scheduling of events within the simulation of hearth record formation

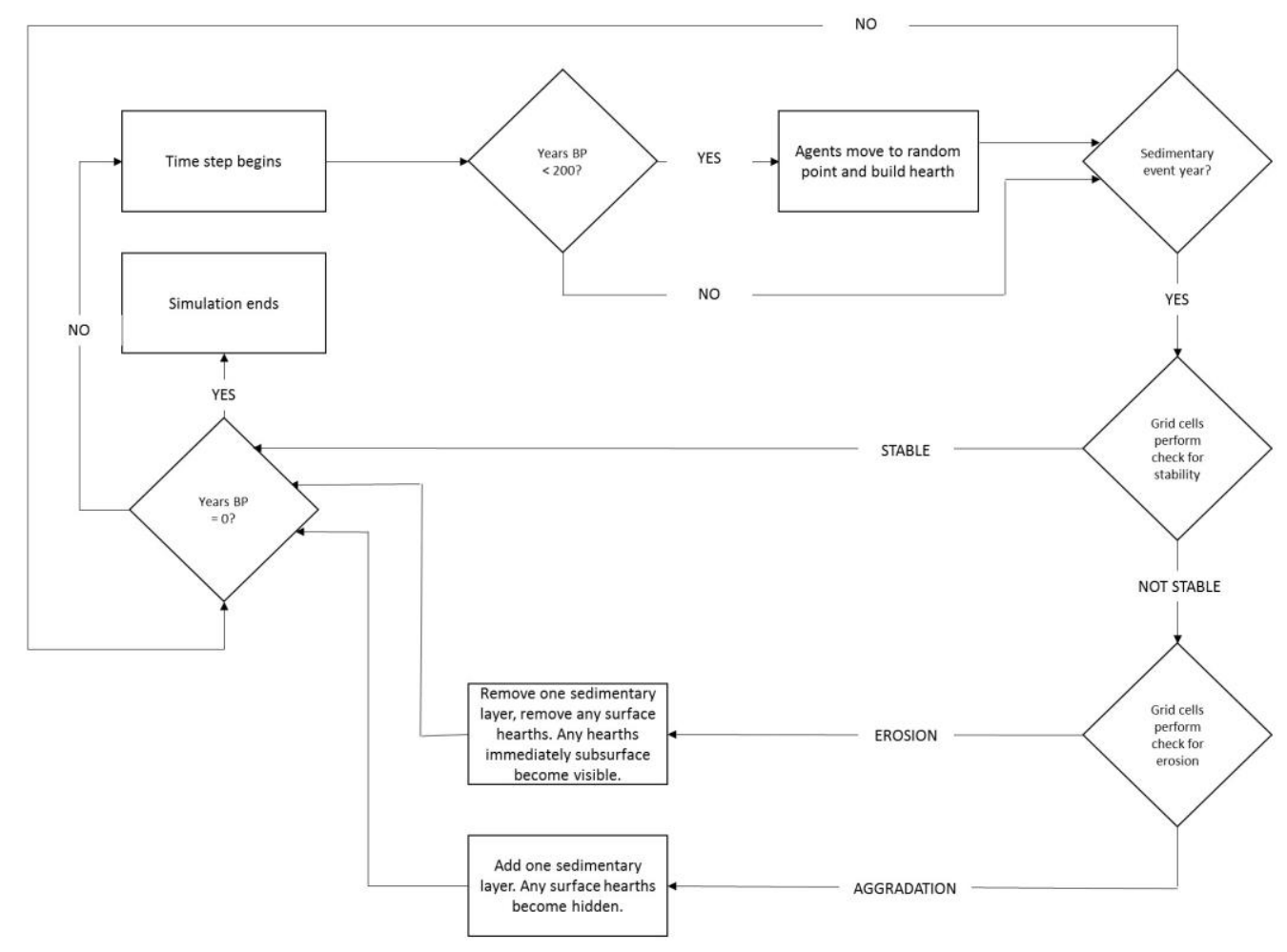


Figure 3: Graphed outcomes from multiple parameter configurations of the simulation. Black envelopes indicate charcoal radiocarbon dates and grey envelopes indicate optical-stimulated luminescence dates from hearth stones. Each envelope contains a plot based on 1000 samples of 100 hearths obtained from simulated surface records.

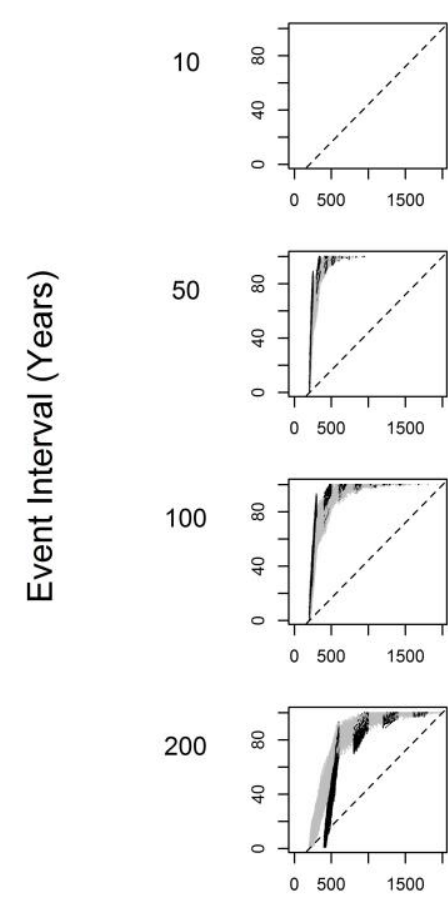

0.1
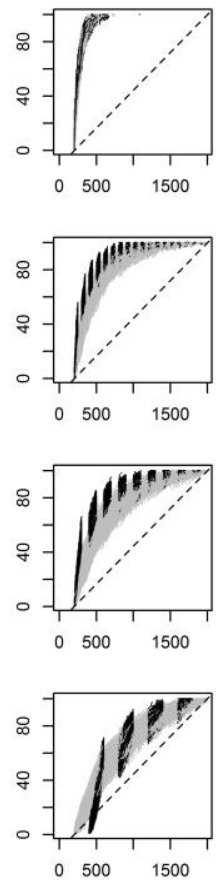

0.3
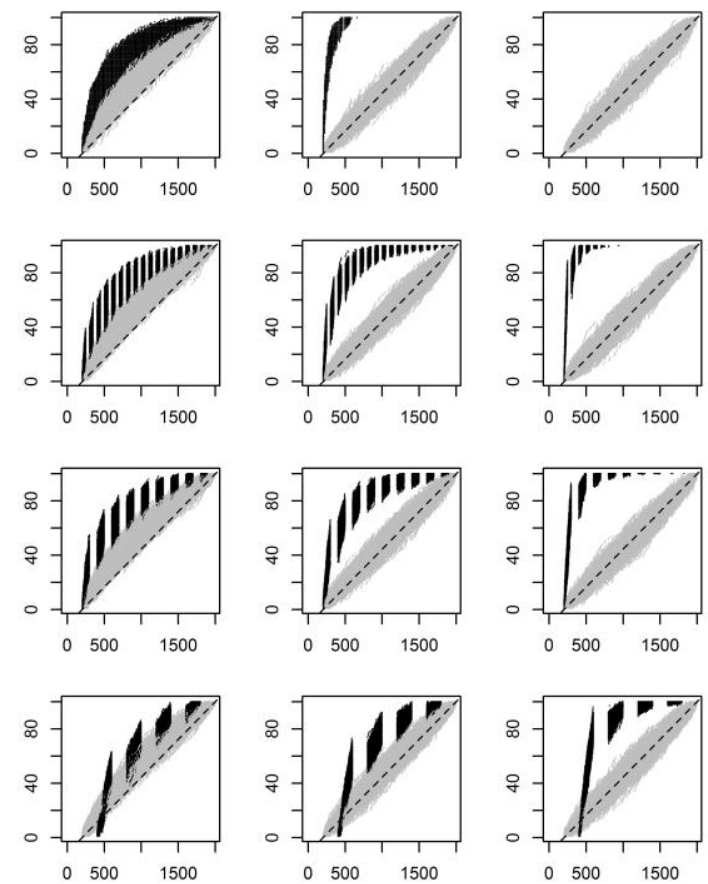

0.5

0.7

0.9

Erosion Probability 
Figure 4: A comparison between calibrated radiocarbon (black, $n=96$ ) dates obtained from charcoal and OSL dates obtained from hearth stones (grey, $n=96$ ). Dates in both proxies are ordered from bottom to top in reverse chronological order. Dots indicate mean age, bars indicate one standard deviation.

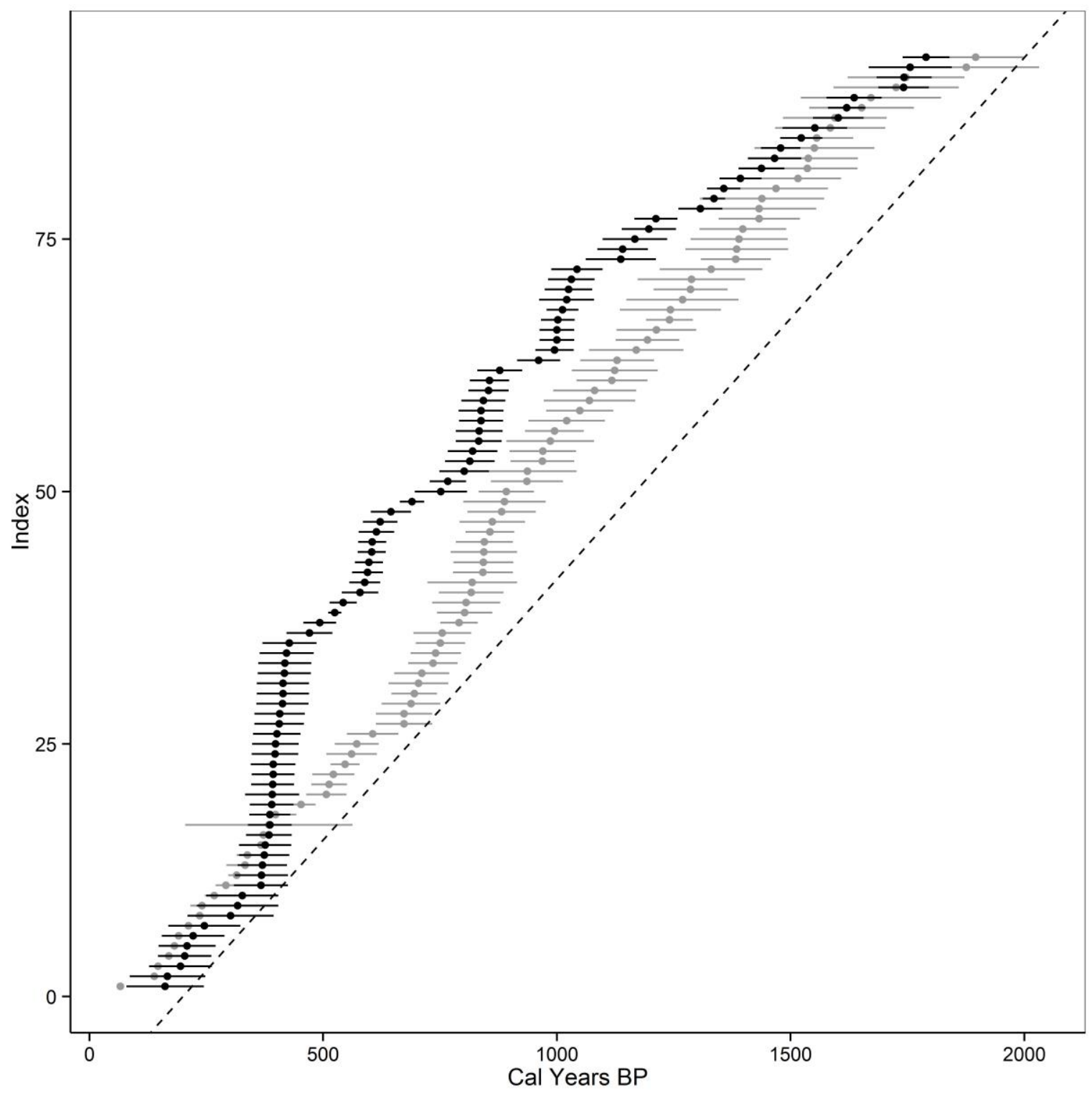

